\title{
POESIA PARA DEPOIS DO FIM DO MUNDO: NICANOR PARRA, A DITADURA MILITAR EA ANTIPOESIA DO APOCALIPSE
}

Hiby

\author{
João Gabriel Mostazo Lopes \\ Universidade de São Paulo (USP)
}

PALAVRAS-CHAVE:

Este artigo investiga a relação entre a obra antipoética do chileno Nicanor Parra (1914-2018) com a questão do fim do mundo, a partir da sua produção literária dos anos 1970-80. Passando pelos problemas enfrentados pela obra no período, discute-se sobre a relação entre a sua poesia e o momento histórico chileno da ditadura militar, a partir do golpe de 1973, chegando à transformação política de Parra nos anos 80 para aquilo que irá ser chamado de "ecopoesia". O funeral do sujeito lírico, que já vinha sendo colocado em questão desde o início da antipoesia de Parra, nos anos 1950, ganha contornos dramáticos a partir das mudanças climáticas e ameaças nucleares que o final do século XX anuncia. Também a saída pelo sermão de pregação, como resposta ao golpe militar e à ameaça da catástrofe ecológica, representa um ponto de especial interesse na trajetória do autor.

\section{ABSTRACT}

This essay aims at the investigation of the relation between the antipoetic works of Chilean poet Nicanor Parra (1914-2018) and the issue of the end of the world, through a reading of his literary production in the years of 1970-80. Going through the problems faced by his poetry in this period, we discuss the relation between Parra's antipoetry and the historical moment of the military coup d'état in Chile, in 1973, arriving at he political transformation that takes place by the 80's, into what will be called 'ecopoetry'. The lyrical subject's funeral, that was announced since the early antipoems, in the 50's, is taken to its last consequences in face of the threat of climatic and nuclear catastrophes in which the late $20^{\text {th }}$ century dwells. Also the religious discourse as a response to the military dictatorship and the ecological crisis represents an interesting point in the author's trajectory.
Antipoesia;

Nicanor Parra;

apocalipse;

ecopoesia.

\section{KEYWORDS}

Antipoetry; Nicanor Parra; apocalypse; ecopoetry. 


\section{Os três tempos da antipoesia}

Antes de entrar no tema propriamente dito, isso é, a antipoesia de Nicanor Parra (Chile, 1914-2018) no período da ditadura militar chilena, convém fazer um breve balanço do que havia sido a antipoesia nos anos 1950-60. Para tanto, sugiro apreender aquela poesia, em si mesma múltipla e complexa, a partir de um de seus aspectos apenas, que nos interessará aqui: o da relação entre o sujeito e a realidade. Proponho, pois, que a antipoesia dos anos 1950-60 seja lida a partir de três movimentos, que dizem respeito a essa relação. Faço duas ressalvas, ainda: a primeira, de que isso de maneira alguma esgota aquele período da obra de Parra, embora possa, espera-se, esclarecer algumas das suas problemáticas; a segunda, que aquilo que chamo de "três movimentos" não correspondem a três "períodos" ou "momentos" da antipoesia dos anos 1950-60, que se sucedem progressivamente, mas dizem respeito a algo como "três tempos", que ocorrem simultaneamente - isso é, esta divisão em três etapas (movimentos, tempos, que seja) é puramente teórica, e não possui força explicativa para a historiografia do desenvolvimento da antipoesia.

Pois bem: é como se o sujeito de Parra naqueles anos 1950-60, ao recusar o "Olimpo" e o poeta "semideus", conforme a sua expressão que se notabilizou, fizesse a opção racional por manter-se conectado com a realidade em tempo integral, buscando uma poesia efetivamente popular. Com efeito, isso é o que move, desde o início, a empreitada antipoética. Daí falar-se em antipoesia: anti o devaneio, a transposição da consciência para outro plano discursivo, imagético, existencial, subjetivo, que a poesia dita tradicional - obscurantista, hermética, séria - promoveria, aos olhos de Parra. Ao manter-se voluntariamente preso ao garrote da realidade concreta - expressada através da linguagem comum, popular, de uma "cultura real" - o sujeito parriano se descola do deslocamento, quer dizer, recusa o distanciamento de tudo o que seja considerado poético. $\mathrm{O}$ primeiro tempo da antipoesia é, portanto, o tempo em que esse sujeito quer recusar a irracionalidade: quer ser um sujeito racional e fazer uma opção racional pelo real.

Segundo tempo: o sujeito, uma vez instalado na realidade cotidiana e concreta, faz ali uma primeira descoberta. A recusa do deslocamento em relação à realidade leva a duas coisas: à seriedade absoluta, ininterrupta e 
total; e à completa loucura. Loucura e seriedade, na realidade, são um e o mesmo instante da consciência. Daí a dupla voltagem do humor e da ironia parriana: os mais completos disparates, contrassensos, ridicularidades e maus-gostos ditos da maneira mais séria possível; daí que Parra pode dizer e repetir: "a verdadeira seriedade é cômica". No limite, está em jogo neste período a mais séria desautorização de si mesmo possível. Desautorização do sujeito enunciador enquanto eu-lírico, deslocamento completo com relação ao próprio enunciado. O segundo tempo da antipoesia é aquele em que o sujeito que buscava a realidade concreta e racional da vida cotidiana, contra os devaneios poéticos, termina encontrando nessa realidade uma prisão manicomial. Nessa fase o sujeito oscila entre o louco que nega ser louco e o louco que afirma a própria loucura com orgulho.

Terceiro tempo: aquilo que era uma oscilação entre sanidade e loucura do Eu é transposto para o mundo: o sujeito descobre que a identidade entre humor e seriedade, loucura e sanidade é um aspecto constitutivo da realidade. E que, portanto, se é um aspecto constitutivo da realidade, é um traço constitutivo também da linguagem: é na linguagem comum que estão as operações mais radicais de distanciamento da realidade. O terceiro tempo da antipoesia é aquele em que a linguagem desloca-se a si mesma e distancia-se de si mesma, e nesse movimento arrasta o sujeito. $\mathrm{O}$ sujeito de Parra nesse momento é aquele que é levado pelo movimento aleatório, imprevisível e contraditório da linguagem movimento este que é o ponto de chegada de uma investigação, lembremos, racional, perfeitamente aceitável, legítima e coerente de uma reivindicação pelo uso comum da linguagem. Parra descobre, como um físico que choca partículas, que o movimento mais natural da linguagem, a prosódia mais cotidiana e comum, é o seu instante de maior invenção e ficção, e o seu momento de enrijecimento formal e métrico - como se percebe pelo uso frequente de decassílabos na poesia tensionada entre forma tradicional e discurso popular desse período, sobretudo a partir do livro Versos de Salón, de 1962.

Repito que esses três tempos ocorrem simultaneamente, no interior da economia formal e subjetiva dos poemas, e, com exceção da particularidade do uso do decassílabo a partir dos anos 1960, não podem ser distinguidos senão teoricamente.

\section{Teologia do desconcerto}

Com o golpe militar de 1973, consumado no bombardeio do palácio da Moneda, no dia 11 de setembro daquele ano, essa relação entre o sujeito e a realidade se altera. Na virada dos anos 1960 para os 70, Parra havia chegado à dissolução quase completa do sujeito lírico, com seu limite na 
experiência dos Artefactos $(1972)^{1}$, poemas visuais curtos que reproduziam ditos populares, ou articulavam slogans que parodiavam a linguagem publicitária, sem que se tivesse clareza de quem era o sujeito que os enunciava. Tratava-se, nos Artefctos, de um sujeito fragmentado, estilhaços de um sujeito resultantes da explosão de uma granada, como Parra definiria anos mais tarde. ${ }^{2}$ Há, a partir da segunda metade dos anos 1970, contudo, uma reconstituição do sujeito no antipoema, e da sua relação com a realidade e as circunstâncias histórias e sociais que o cercavam. Essa reconstituição se dará, defenderemos, sob o signo do desconcerto.

Vou tomar de partida a ideia sugerida por Bernardo Subercaseaux $(1997)^{3}$ de que o golpe militar chileno não é apenas uma transformação no sistema político, mas também no sistema de ideias e da cultura no país. Como Subercaseaux vai reconstituir, produz-se a partir daí uma literatura da desconjuntura, do desconcerto, "uma literatura de máscaras".

\begin{abstract}
A lo acontecido en el país se sumó el conocimiento de lo que ocurría en los llamados "socialismos reales", la caída del muro de Berlín y la desarticulación paulatina del sistema soviético y del ideario que lo sostenía. El quiebre de ideales trajo consigo una poderosa resaca sociológica, que revolvió y desordenó la subjetividad de los afectados. Un estado individual y colectivo que puede describirse como de desconcierto. [...] Es una literatura de mascaras que sintoniza el desconcierto con el lenguaje del delirio. ${ }^{4}$
\end{abstract}

Para Subercaseaux, o golpe é, portanto, um marco na história da subjetividade chilena (ver um bombardeio no centro de Santiago, mortos pelas ruas, tortura, desaparecidos, intervenções militares nas universidades, professores perseguidos, violação das correspondências, tudo isso, segundo Subercaseaux, provocou um terremoto cultural, ético e subjetivo na população chilena).

Como Parra reagiu a esse desconcerto da subjetividade e como ele também articulou uma "literatura de máscaras"? Trata-se de defender a ideia, aqui, de que esse novo sujeito mascarado da poesia parriana caracteriza-se não mais pelo movimento do sujeito através do "arrastão" da linguagem, como nas décadas anteriores - pela loucura da seriedade e pela profanação do sagrado pelo secular - mas pela inadequação do sujeito à realidade - pela imobilidade do sujeito diante de uma realidade que se

\footnotetext{
${ }^{1}$ Cf. PARRA, Nicanor. Artefactos. In: Obras Completas \& algo +. Barcelona: Gutenberg, 2006.

${ }^{2}$ Cf. MORALES, Leonidas. Conversaciones con Nicanor Parra. Santiago: Tajamar, 2006.

${ }^{3}$ Cf. SUBERCASEAUX, Bernardo. Historia de las ideas y de la cultura en Chile. vol. 1-3, Santiago: Universitaria, 1997.

${ }^{4}$ Idem, ibidem, pp. 253-67.
} 
afasta dele, pela seriedade absoluta da pregação religiosa e pela profanação do secular pelo sagrado.

Entre 1977 e 1979, Parra publicou dois volumes de poesia, Sermones y prédicas del Cristo de Elqui e Nuevos sermones y prédicas del Cristo de Elqui5, respectivamente. Os dois livros são a resposta algo tardia, mas não menos contundente aos eventos ocorridos no país quatro anos antes, que implicariam ao longo das quase duas décadas seguintes transformações na experiência política, social e cultural chilena, levadas a cabo por uma rígida ditadura militar. Parra havia publicado a antologia Obra Gruesa em 1969, um ano antes de Salvador Allende assumir a presidência, em que recolhia a sua produção poética desde 1954. Em 1972, durante o mandato do presidente socialista, conforme dito, saíram os poemas visuais Artefactos, além da coletânea em inglês Emergency poems. Veio o golpe, veio Pinochet, e a resposta de Parra tardaria ainda quatro anos para sair. Nela emerge a figura excêntrica e paranoide do Cristo de Elqui, alterego de Domingos Zárate Vega (1898-1971), figura popular chilena dos anos 1930, místico que dizia ser o messias, e que havia morrido seis anos antes no esquecimento. ${ }^{6}$ Os sermões do Cristo de Elqui marcam uma guinada discursiva na antipoesia de Parra, dessa vez na voz do pregador religioso. É a partir dessa guinada que o autor irá refletir, criticar e denunciar o Chile da ditadura, bem como em seguida, já nos anos 1980, o mundo que se abria com o fim da Guerra Fria.

Assim, os temas históricos do período, como a tortura e a perseguição política, se encontram nas pregações do Cristo de Elqui como que amalgamados pelo discurso religioso do messias autoirônico, que vai ao âmago dos problemas do seu tempo justamente tomando dele uma distância segura, operando uma espécie de curto-circuito na temporalidade histórica do seu discurso. Vejam-se por exemplo as referências como que "cruzadas" à ditadura que aparecem no poema XXIV, do primeiro volume dos sermões:

\author{
XXIV \\ Cuándo los españoles llegaron en Chile \\ se encontraron con la sorpresa \\ de que aquí no había oro ni plata \\ nieve y trumao ${ }^{7}$ sí: trumao y nieve \\ nada que valiera la pena \\ los alimentos eran escasos \\ y continúan siéndolo dirán ustedes
}

\footnotetext{
${ }^{5}$ Cf. PARRA, Nicanor. Nuevos sermones y predicas del Cristo de Elqui. Santiago: Universidad de Chile, 1979.

${ }^{6}$ Em conversa com Leonidas Morales, Parra se recorda de ter visto o Cristo de Elqui um par de vezes, na juventude, e de tê-lo ouvido pregar, e revela ter ficado muito impressionado com a figura, já então. In: MORALES, Leonidas. Op.cit.

7 Tipo de solo seco, típico do Chile, de origem vulcânica.
} 
es lo que yo quería subrayar el pueblo chileno tiene hambre sé que por pronunciar esta frase puedo ir parar a Pisagua ${ }^{8}$ pero el incorruptible Cristo de Elqui no puede tener otra razón de ser que la verdad el general Ibañez me perdone en Chile no se respetan los derechos humanos aquí no existe libertad de prensa aquí mandan los multimillonarios el gallinero está al cargo del zorro claro que yo les voy a pedir que me digan en qué país se respetan los derechos humanos. ${ }^{9}$ bíblica:

E o anterior, que termina com um desafio aos torturadores, em chave

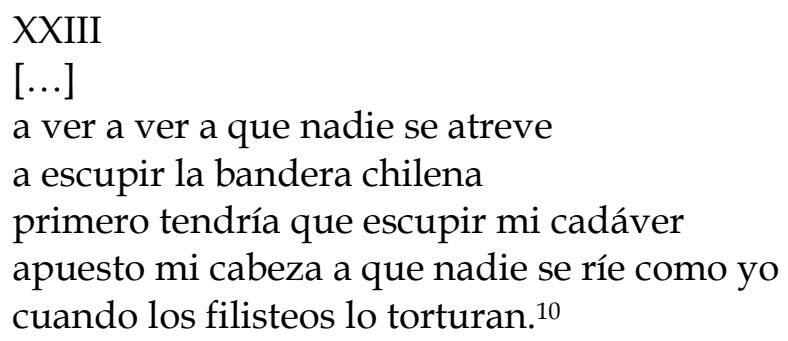

Tudo é dito de maneira muito direta, mas se passa como que num passado já sepultado. O Cristo de Elqui vive em uma ditadura - mas não a ditadura de Pinochet, e sim a ditadura do general Ibañez (Carlos Ibañez del Campo, que foi presidente do Chile em duas ocasiões, entre 1927-31 e 1952-58). Isso que estou chamando um de curto-circuito na temporalidade histórica do discurso, entre a situação política chilena contemporânea e a denúncia da sua violência, não se via nos antipoemas da década anterior. Paradoxalmente, note-se que a fase mais politizada e engajada de Parra é quando a obra se assume mais "ficcional", sob a roupagem da clownesca figura histórica recuperada do místico de Elqui. Sobre isso o autor lembra, em conversa de 1989 com Leonidas Morales, que:

... a mí se me hace difícil pensar que sin golpe militar yo hubiera llegado al Cristo de Elqui. Además yo necesitaba una máscara por razones de supervivencia personal, a través de la cual decir algo. ${ }^{11}$

\footnotetext{
8 Região inóspita na costa do Chile, que serviu como campo de detenção e extermínio de opositores do regime de Pinochet, durante a ditadura militar.

${ }^{9}$ In: PARRA, Nicanor. Sermones y predicas del Cristo de Elqui. Santiago: Universidad de Chile, 1977.

${ }^{10}$ Idem, ibidem.

${ }^{11}$ PARRA, 1989. In: MORALES, Leonidas. Op.cit., p. 117.
} 
Natural: se essas coisas forem ditas, levam o sujeito para o campo de concentração. E ainda assim, elas são ditas, mais ditas do que nunca, resguardadas que estão no próprio absurdo da situação. Um pouco antes, na mesma conversa, Parra reflete mais a fundo sobre a relação entre o Cristo de Elqui e a ditadura militar:

... después del golpe, uno se pregunta, bueno, se perdió todo? Se
perdió toda la posibilidad del discurso tradicional? Todo se va a
reducir al lenguaje militar? No, pues. A lo mejor nosotros con
restos del discurso tradicional podemos tratar de armar un
espantajo.12

É nessa transformação do sujeito de uma situação histórica em espantalho que a realidade se apresenta de maneira tão a céu aberto que, quando irrompe, vem na forma da mais incrível ficção. Outro paradoxo, correlato, é o que nos interessa mais aqui: é quando o fio desencapado da ironia se torna mais carregado. Ironia tão irônica que pode dizer as coisas diretamente, como são, porque o sujeito que se vê em meio aos acontecimentos da década de 1970 no Chile já não mais precisa se distanciar do seu enunciado - o seu enunciado vem já em si mesmo distanciado, na forma de um processo histórico a um só tempo impossível e realizado. A ironia do Cristo de Elqui é a ironia da sua inadequação às circunstâncias que o cercam. Desse deslocamento é que a verdade vem literalmente à tona, provocando uma mutação nos antipoemas, que se convertem apropriadamente em sermões - o gênero tradicional da revelação. Cabe sublinhar aqui, ainda, que o Cristo de Elqui de Parra é basicamente o oposto exato de um pseudônimo: todos sabiam que era Parra quem escrevia os poemas, e o autor nunca fez questão de esconder a sua verdadeira identidade. Pelo contrário, a ironia com a qual Parra fazia questão de ser introduzido, antes de leituras públicas dos seus poemas nos anos 1970, como "Nosso Senhor Jesus Cristo", para em seguida aparecer de jaqueta jeans e óculos (como em um recital em 1977 em Santiago, do qual há registro em vídeo) é o que diferencia esta máscara de outras que outros artistas, em períodos de repressão, se veem obrigados a usar para driblar a censura e a perseguição política. O Cristo de Elqui é o que poderíamos chamar, paradoxalmente, de uma máscara que se veste às claras mas esse paradoxo de estar sempre às claras não é o que caracteriza toda e qualquer máscara, afinal? De todo modo, não devemos nos enganar: o fato de ser vestida às claras, de modo quase performático por Parra nas suas aparições em público, carregando o nome evidentemente falso de "Cristo de Elqui", é o que possibilita que a mensagem político-religiosa que ele deseja transmitir através das pregações atravesse a cortina da repressão -

12 Idem, ibidem, p. 116. 
isso sem levar em conta o fato, é preciso que se diga, de que por diversas razões as quais não sabe aqui desdobrar Parra não foi fisicamente perseguido pela ditadura, como foram muitos artistas do período - ao menos não no sentido de ter de se exilar, ou de ter seu posto universitário cassado. Ainda assim, para dizer de modo bastante sintético, com o Cristo de Elqui é como se Parra "dobrasse a aposta" da ditadura. Como isso se dá?

Em primeiro lugar, através da anunciação. O leitor notará, diante dos sermões do Cristo de Elqui, um uso da linguagem bastante particular. No poema IX, esse uso é referido diretamente, como uma "língua vulgar": "y perdonen si me he expresado en lengua vulgar/ Es que esta es la lengua de la gente" ("IX", Sermones y prédicas de Cristo de Elqui, 1977). Apesar desse recurso à linguagem banal e vulgar, contudo, é preciso ter em mente contudo que a antipoesia de Parra não é uma poesia antitradição - como pode ser erroneamente interpretado. É uma poesia que se opõe àquilo que o autor chamava de "vício do pedantismo" na cultura ocidental - a ideia de que o poeta é um sujeito extraordinário, cuja experiência singular não tem par entre os outros mortais, o poeta como aquele que vê o que os outros não veem e diz o que os outros não podem dizer. A antipoesia opõe a isso, que Parra dizia ser um vício, um outro vício, o vício da cultura popular, que é o vício da vulgaridade. Vulgaridade, portanto, aqui, é a língua vulgar da experiência comum da linguagem - o uso da linguagem que não é próprio a um ou outro indivíduo e que, justamente por definição, não pode ser "privatizado" dessa maneira.

Ainda assim, e mesmo para o leitor acostumado a uma importante tradição de poesia prosaica e cotidiana, que tem representantes em toda a América Latina, e muito especialmente na poesia brasileira, os Sermões do Cristo de Elqui podem causar algum espanto. Pois a linguagem aqui se vulgariza a tal ponto que beira, por vezes, o "mal escrito". Há, aqui, quebras de raciocínio, frases que não se completam, pensamentos que se atropelam, mudanças súbitas de assunto, repetições, redundâncias e insistências injustificadas em certos temas - como a morte da mãe, acontecimento capital que leva o Cristo a iniciar sua pregação, e que volta e retorna nos poemas sempre de uma maneira um tanto atravessada, esquisita. Tudo isso vem daquilo que Parra chama de os "recursos escassos" do seu orador. E ainda assim, é uma poesia lógica, de raciocínio sóbrio, cujas argumentações fazem muitas vezes perfeito sentido, fruto da capacidade que esse orador tem de articular os seus pobres recursos de um "analfabeto que nunca pisou na porta de uma escola":

Yo creo que es una superación de todo. Porque el tipo aparentemente se presenta provisto de recursos muy limitados. Pero él es capaz de relacionar eses recursos. Yo he llegado por primera vez a lo que podría llamarse una poesía de la sintaxis. Que no es una poesía a base de relámpagos con clave, sino que 
el tipo se desplaza a lo largo de un discurso. Eso no podría hacer el sujeto antes, sino que a partir de movimientos casi peristálticos no más. En cambio acá no. Acá hay in desarrollo. Es decir, es una poesía de logos. Y eso yo lo considero un paso adelante. Claro que en último termino es un logos enfermo. Pero es un logos. ${ }^{13}$

Se essas questões estão sendo todas colocadas em jogo no primeiro volume dos sermões, há um desenvolvimento na passagem para o segundo e, em 1979, aparece o mais impressionante ainda Nuevos sermones y predicas del Cristo de Elqui. O que eram punhaladas desferidas por uma ironia quase insuportável, dado o contexto no qual se conformava, dá lugar a meditações igualmente irônicas, mas que na aparência deixam de burlar, por assim dizer. Algo estranho acontece aqui, com o humor parriano: ele se torna sério, mais sério do que jamais foi. A natureza das pregações deste segundo Cristo caminha para uma verdadeira declaração de princípios, que já subjazia às declarações dos sermões anteriores, embora estas fossem menos reflexivas, mais imagéticas. De fato, uma poesia de logos, de argumentação, e de uma lógica impecável se instala definitivamente. $\mathrm{O}$ sermão/poema XVI, ainda em Sermones y prédicas..., dizia já:

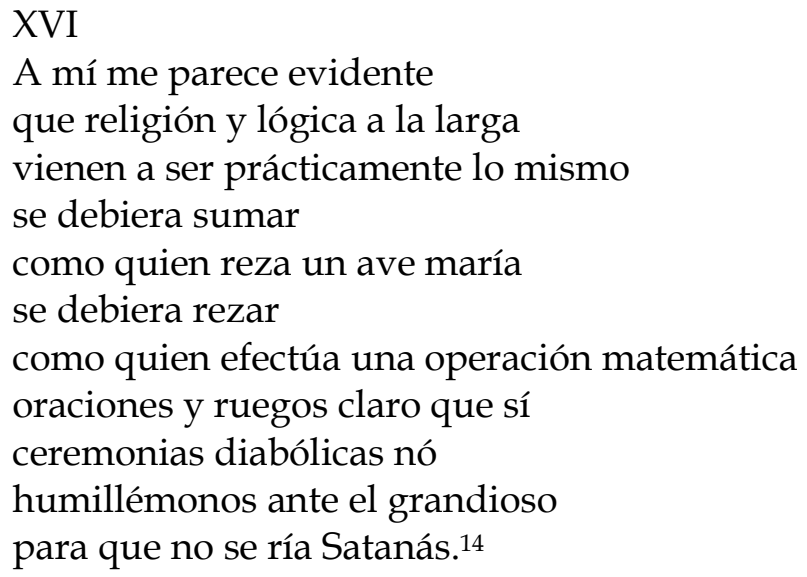

O sermão XLII, por sua vez em Nuevos sermones..., propõe a ideia de que aquilo que a esquerda procurava na época, baixo os jargões de luta de classes, comunismo etc., era nada menos que o Espirito Santo cristão. $\mathrm{O}$ que antes, na antipoesia parriana dos anos 1950-60, era a profanação do sagrado pelo secular se transforma em profanação do secular pelo sagrado: a verdade da política é o Espírito Santo. Pelo menos é o que diz o Cristo de Elqui, esta espécie de Inri Cristo chileno:

\section{XLII}

La presencia del Espíritu Santo

\footnotetext{
${ }^{13}$ PARRA, 1989. In: MORALES, Leonidas. Op.cit., pp. 117-8.

14 Idem, 1977.
} 
se percibe con toda nitidez en la mirada de un niño inocente en un capullo que está por abrir en un pájaro que se balancea sobre una rama

dificulto que alguien pueda poner en duda la presencia del Espíritu Santo en un pan recién sacado del horno en un vaso de agua cristalina en una ola que se estrella contra una roca

¡ciego de nacimiento tendría que ser!

hasta un ateo tiembla de emoción ante una sementera que se inclina bajo el peso de las espigas maduras ante un bello caballo de carrera ante un volkswagen último modelo

lo difícil es saber detectarlo donde parecería que no está en los lugares menos prestigiosos en las actividades inferiores en los momentos más desesperados

ahí falla el común de los mortales ¿quién podría decir que lo percibe en los achaques de la ancianidad en los afeites de las prostitutas en las pupilas de los moribundos?

y sin embargo también está ahí pues lo permea todo como el sodio ¡qué lo digan los Padres de la Iglesia!

Arrodillémonos una vez más en homenaje al Espíritu Santo sin cuyo visto bueno nada nace ni crece como tampoco muere en este mundo. ${ }^{15}$

"Até um ateu treme de emoção", é como o pregador quer convencer os fiéis. O Cristo de Elqui segue à risca a própria doutrina: é no ato falho da sua fé que ele se une com as prostitutas, as crianças, com os velhos, desvalidos e moribundos que são os verdadeiramente golpeados pela forma de violência permanente e diária à qual são submetidos. Essa

15 PARRA, 1979. 
doutrina é a do pregador que opera a fé através da lógica, levando a cabo algo que poderíamos chamar de uma ironia do contraditório absoluto:

\author{
XLI \\ Todo puede probarse con la Biblia \\ por ejemplo que Dios no existe \\ por ejemplo que el Diablo manda más \\ por ejemplo que Dios \\ es masculino y femenino a la vez \\ o que la Virgen María era liviana de cascos \\ basta con conocer un poco el hebreo \\ para poder leerla en el original \\ e interpretarla como debe ser \\ es cuestión de análisis lógico \\ Tienen razón los amigos escépticos \\ todo puede probarse con la Biblia \\ es cuestión de saberla barajar \\ es cuestión de saberla adulterar \\ es cuestión de saberla descuartizar \\ como quien descuartiza una gallina: \\ ¡pongan otra docena de cervezas!16
}

A máscara com que Parra veste o sujeito da sua poesia a partir da segunda metade dos anos 1970 é portanto a máscara do discurso mais tradicional, menos irônico possível: o discurso do sermão religioso. Mas, exatamente por essa razão, articulado por um sujeito semianalfabeto que, não obstante maneja as palavras com maestria lógica, este é o discurso mais inadequado às circunstâncias.

A ironia final do Cristo de Elqui, dessa inadequação da máscara à circunstância, consiste em ser o mais sério possível - e o mais chato. $\mathrm{O}$ Cristo, além de meditações teológicas profundas, dá a torto e a direito conselhos aos seus fiéis. Em meio à brutal ditadura militar chilena, o gesto ganha ainda mais amplitude. Quem coloca a questão em termos precisos é, novamente, o próprio autor:

Mientras más chata y más plana, mejor! Porque, imagínate tú, cuando se pone a dar consejos, cuando da sus consejos de carácter práctico... Eso es lo más chato que hay, pues hombre!17

Marca maior, essa "chatice", da relação ambivalente entre distanciamento e aproximação do discurso com a sua situação histórica, que será o ponto de virada a partir do qual, na década seguinte, a antipoesia de Parra passa a como que intuir uma nova correlação de forças

\footnotetext{
16 PARRA, 1979.

17 Idem, 1989. In: MORALES, Leonidas. Op.cit., p. 118.
} 
políticas, históricas e éticas que apontam, num limiar precoce do século XXI, o deslocamento da atuação política para o eixo da sobrevivência, do qual saltam as figuras apocalípticas da catástrofe ecológica e nuclear e do abandono do sujeito humano à própria sorte.

\section{Ecologia do apocalipse}

Às portas dos anos 1980, não há como ler a ironia entre catástrofe política e pregação destes poemas de Nicanor Parra sem colocá-los sob a luz da perspectiva ecologista que ele irá adotar a partir de então, e que guarda relações profundas com a questão da circunstância política e social em que emergem os seus sujeitos mascarados. A figura teológica da enunciação, elaborada às últimas consequências no Cristo de Elqui, invadirá os poemas curtos de "Ecopoemas" (1982) ${ }^{18}$, publicados em Poesía política, de 1983, em que, por exemplo, o próprio Deus dá à humanidade um irônico recado:

Francamente no sé qué decirles

estamos al borde de la III Guerra Mundial

y nadie parece darse cuenta de nada

si destruyen el mundo

¿creen que yo voy a volver a crearlo? ${ }^{19}$

São os últimos suspiros da Guerra Fria, e, na visão de Parra, a dicotomia entre esquerda e direita que organizara o mapa mundial durante quatro décadas teria que dar lugar a uma perspectiva de "sobrevivência".

Ahí hay una paradoja. Yo cuando me puse a escribir los Sermones, la idea que tenia era que el sermón y la predica están de más y que es una locura sermonear. Que no se debe hacer, y que en último término es ridículo. Sin embargo, después de que se hicieron los Sermones y predicas, me considero en este momento un predicador. Ahí hay una paradoja, ah? Pero claro que yo me las arreglo para salir de la trampa, permitiéndome el lujo de operar también en el plano antiecológico. Aparentemente antiecológico. Sería el ejemplo que te di anteriormente: 'Yo no sé para qué tanta alharaca. Ya sabemos que ele mundo se acabó' ["Ecopoemas", Poesía política, 1983]. [...] Es decir, qué bueno qué que nosotros podamos darnos cuenta, y qué bueno es también poder jugar con el apocalipsis. Entonces, estamos llevando a la práctica de todas maneras el proyecto ecologista,

${ }^{18}$ Cf. PARRA, Nicanor. “Ecopoemas”. In: Poesía política. Santiago: 1983.

19 Idem, "Ecopoemas", 1982. 
un proyecto de vida lúdica. Juguemos hasta con el apocalipsis. Con la extinción, la muerte total. ${ }^{20}$

O tema do apocalipse em Parra é longo, e tem a ver com uma transformação da perspectiva temporal que o autor intuiu (quem sabe entre os primeiros a fazê-lo) no interior da organização política e social do seu tempo - mas não só: também na maneira como passava a se reproduzir a partir de então a própria estrutura do discurso. Esse conjunto de noções ou intuições remonta aos Sermones, e se desdobra com clareza nos poemas recolhidos em Hojas de Parra, de 198521, volume no qual por um instante "desaparece no tan solo el hombre, el sujeto, sino que desaparece el hablante lírico también. Hay que hacerle los funerales también al hablante lírico" 22 - como no caso limite de "Los 4 sonetos del apocalipsis":

\section{LOS 4 SONETOS DEL APOCALIPSIS}

1

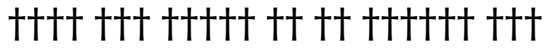

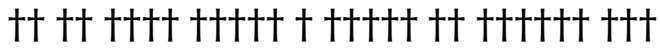

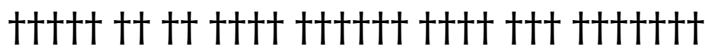

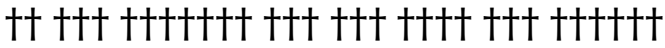

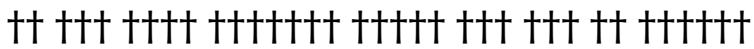

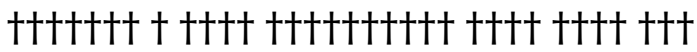

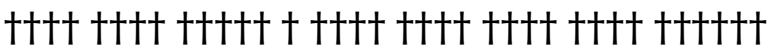

t+t +t+ t+t+t+t+t +t t+ t+t+ t+t+ t+t+t

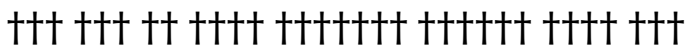

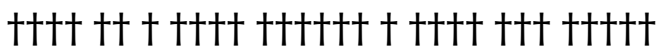

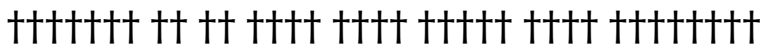

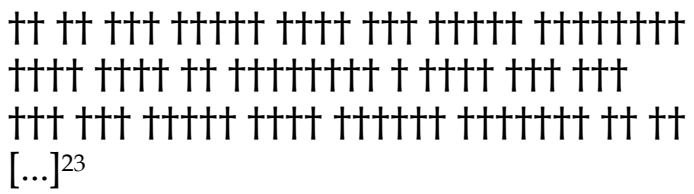

Os três sonetos seguintes seguem o mesmo padrão do primeiro. Essa transformação da temporalidade, com fim do discurso semanticamente articulado que essa transformação implica, diz respeito a algo que está diretamente ligado ao fim da Guerra Fria, e que se convencionou chamar de "fim da História", na glosa que tanto se fez já da famigerada sentença de Fukuyama. Mas "fim da História", à parte o ridículo óbvio da

\footnotetext{
${ }^{20}$ PARRA, 1989. In: MORALES, Leonidas. Op.cit., p. 115.

${ }^{21}$ Cf. PARRA, Nicanor. Hojas de Parra. Santiago: Talleres Editorial Deriva, 2016.

22 PARRA, 1989. In: MORALES, Leonidas. Op.cit., p. 122.

23 Idem, 1985.
} 
expressão, nesse caso, quer dizer duas coisas: a primeira, menos diretamente imputável às intuições de Parra, mas não obstante imprescindível para entende-las, de que a colonização absoluta da política pela esfera da economia - da qual o que se chama de "neoliberalismo" seria apenas o substrato ideológico, sem qualquer força teórica ou explicativa que seja - a partir dos anos 1970-80, e mais intensamente com a financeirização das ex-economias socialistas como a China, colocou o capitalismo global num estado de permanente desgoverno - quase literalmente: não haveria governo capaz de regular ou orientar o ímpeto desenfreado de autorreprodução do capital a partir do momento em que a economia se torna uma economia financeira; a crise de 2008, com os conhecidos excessos dos players de Wall Street que levaram à constituição das famosas "bolhas", seria, nesse sentido, apenas o marco que permite constatar que de fato a História, no sentido de movimento humano politicamente orientado, terminou. Igualmente a crise da União Europeia, pós-2008, muito tem a ver com uma asfixia do sistema político frente o poder da máquina financeira do continente, fruto de uma unificação apenas monetária, com o Euro, desacompanhada de qualquer unificação política real. Tudo, evidentemente, entre a catástrofe e a falácia, pois não há mercado livre o bastante, como se sabe, que exista sem qualquer relação com o Estado; basta ver a inflação, no mesmo período, do Estado norteamericano, transformado numa máquina de guerra hi-tech. ${ }^{24} \mathrm{Ou}$ a quantidade colossal de dinheiro público aplicada pelo FED para resgatar as empresas americanas que quebraram na crise - o que foi repetido tatibitate por todo o planeta, salvo raríssimas exceções.

A segunda maneira, mais próxima do que Parra estava intuindo à época, é o fato de que, com a derrocada dos estados socialistas e a entrada da humanidade na chamada "era neoliberal" - precoce no Chile, já com Pinochet e os seus Chicago Boys ${ }^{25}$ - , entra definitivamente em crise a ideia de futuro. Se durante a Guerra Fria o medo do apocalipse nuclear convivia ainda em larga medida com a possibilidade da Revolução - basta notar a ironia básica de um mundo que, ao mesmo tempo em que introduz exercícios de sobrevivência para um possível ataque nuclear, convive com uma série de convulsões políticas de toda ordem, como era o mundo dos anos 1960 - , com o seu fim anunciado, e inaugurado o que Paulo Arantes chamou de "o novo tempo do mundo", ficou, no comentário perspicaz de

\footnotetext{
${ }^{24}$ Para um balanço geral de como isso foi pensado pelos próprios norte-americanos, vale o interessantíssimo ensaio de Paulo Arantes, "Notícias de uma guerra cosmopolita". In: ARANTES, Paulo. Extinção. São Paulo: Boitempo, 2007.

${ }^{25}$ Grupo de economistas próximos ao governo militar chileno, que elaboravam a sua política econômica, quase todos formados pela Escola de Chicago, nos EUA, sob a tutela do ideólogo neoliberal Milton Friedman.
} 
Fredric Jameson, mais fácil pensar a extinção da espécie humana do que uma mudança mínima no sistema econômico e político global. ${ }^{26}$

Isso tudo importa e interessa porque é esse o mundo que as profecias apocalípticas do Cristo de Elqui ou de "Ecopoemas" (1982) estão anunciando: um mundo sem futuro. Ao contrário absolutamente do que sugere José Alberto de la Fuente (2007) ao caracterizar o ecologismo de Parra como "una estética que se invalida porque su ecoideología excluye de su reflexión un vector (utopia) para avanzar hacia una nueva cultura" 27 , essa exclusão da utopia não é apenas uma escolha estética, mas um aspecto do próprio mundo político e social que está se iniciando. Como se o que diz Hamlet para Horácio, no quinto ato, tivesse se transformado definitivamente na sentença de um mundo que deixou de existir: "If it be now, 'tis not to come; if it be not to come, it will be now; if it be not now, yet it will come - the readiness is all." 28 Isso é: estar preparado para a antecipação imprevisível do amanhã já não parece mais ter nada a ver com a experiência temporal contemporânea, enclausurada no limbo de um presente eterno em que "estar preparado" já não faz nenhum sentido, pois já não é possível qualquer acontecimento, salvo o acontecimento da "morte total" de uma catástrofe ecológica ou nuclear. No fim da política nos tornamos meros sobreviventes - e governar passa ser gerir os corpos vulneráveis que devem sobreviver, descartando em favelas mundo afora o exército de reserva do qual o capitalismo já não precisa - os "pedestres", que Parra elegerá como sujeitos políticos absolutos da sua poesia ecologista:

PEATONES
Héroes
anónimos
de
la
ecología 29

Diante desse mundo que, aos olhos do antipoeta, se abre para ser pregado, a solução, para Parra, a única solução possível, seria, portanto,

\footnotetext{
26 "Someone once said that it is easier to imagine the end of the world than to imagine the end of capitalism. We can now revise that and witness the attempt to imagine capitalism by way of imagining the end of the world". In: JAMESON, Fredric. "Future city", New Left Review, n. 21, mai/jun 2003.

27 "Disparates religiosos y políticos en la poesía de Nicanor Parra". Literatura y linguística, n. 18, Santiago, 2007.

${ }^{28}$ Hamlet, ato 5, cena 2. In: SHAKESPEARE, William. The Oxford Shakespeare - The complete Works, (org. G. Taylor; S. Wells). Oxford: Oxford Press, 1991, p. 686. A frase ainda faz sentido hoje, porém, justamente no âmbito do sistema financeiro, atravessado que este é por uma moralidade do empresário versátil, prevenido e arrojado, capaz de antecipar subidas e descidas do mercado. Fui recentemente informado, a título de curiosidade, que essa citação de Hamlet é a preferida de um importante executivo de uma grande instituição financeira brasileira.

29 "Ecopoemas", 1982.
} 
jogar com o apocalipse, num movimento, como já se viu segundo o próprio autor, "antiecológico na aparência".

A ver com calma do que se trata essa "aparência", é preciso ter em mente que o risco que se põe diante do antiecologismo parriano é uma leitura puramente teológica da sua relação com a catástrofe. Como se a catástrofe, na medida em que é a única coisa capaz de acordar a humanidade para a necessidade de uma organização coletiva, sob a ética universal da sobrevivência, fosse uma espécie de "benção disfarçada", vinda com a providência de proporcionar, como último recurso, a realização da utopia imanente de uma comunidade igualitária e pacífica. Como se a sociedade que levou à ameaça nuclear precisasse ser destruída para dar lugar à nova sociedade lúdica que os antipoemas prometem. Ao contrário, o caminho enviesado que o logos de Elqui e o catastrofismo de "Ecopoemas" atravessam até a utopia é um caminho propriamente transcendente, no sentido de que, posta de lado a perversão dessa teologia cínica, o que se estabelece com esse raciocínio é que a comunidade pósapocalíptica só se vislumbra através da imagem da catástrofe, que é o seu contraponto radical. E uma vez que a iminência da catástrofe é real, também é real a possibilidade de que ela seja evitada. Não à toa a própria ideia de uma ética da ecologia está associada a uma espécie de "assegurar que mais tarde o futuro ainda esteja aqui": colocar-se após a catástrofe é a única maneira de desviar o curso do destino que necessariamente levaria a ela. Por isso "antiecológico na aparência", isso é, mais uma vez o contrário do que José Alberto de la Fuente deseja ver ao caracterizar a dialética da antipoesia como "una dialéctica de círculo cerrado más que la de una en espiral", em que as contradições e becos sem saída lógicos não moveriam o sujeito adiante, na tarefa de resolver os problemas, mas o paralisariam. ${ }^{30}$ Mas o princípio do qual o ecologismo catastrofista de Parra parte é precisamente o de que esse "chamado à ação" por si só não é o bastante para pôr o sujeito em movimento; ao contrário, para mover-se o sujeito precisa primeiro

\footnotetext{
30 A perspectiva que eu adoto aqui, está claro, é radicalmente oposta à adotada por Fuente. $\mathrm{O}$ problema do ensaio de Fuente, me parece, é tomar a poesia e as declarações de Parra pelo seu "valor de face", incapacitando a leitura para os mecanismos internos que a ironia e a contradição realizam no texto parriano. O ensaio tem momentos quase cômicos, como quando Fuente reprime Parra por ter respondido a uma pergunta sobre os 500 anos do descobrimento da América dizendo que não conhecia a História, mas conhecia Física e Matemática muito bem; Fuente dispara, claramente não entendendo a piada: “CCómo leer esto último? ¿Un candidato al Nobel que se ufana en no conocer la historia?". De todo modo, aparte esses momentos em que a crítica dá lugar ao comentário, não parece ocorrer a Fuente por exemplo que o "yoísmo" do Cristo de Elqui é o "yoísmo" de um yo que não tem qualquer domínio sobre o próprio yo, ou que o descompasso do eu-lírico parriano nos Sermones... com relação à fidelidade histórica, biográfica e conjuntural do verdadeiro Cristo de Elqui revela o interesse de um contexto, precisamente, de decompasso conforme procurei indicar aqui. Isso a não ser que eu, por acaso, tenha perdido também alguma piada. In: FUENTE, José Alberto de la. "Disparates religiosos y políticos en la poesía de Nicanor Parra", Literatura y lingüística, n. 18, Santiago: Universidad Católica Silva Henríquez, 2007.
} 
perceber que não há absolutamente nenhum caminho pela frente. A perspicácia da lógica profética-catastrófica parriana é que ela incorpora radicalmente a terra arrasada de que se fez o futuro como traço elementar, já dado, e desse cenário desolado surgem as vozes que anunciam o óbvio: que o mundo está em vias de desaparecer, que ele já desapareceu. Lembremos ainda que toda a antipoesia começa após a catástrofe, após o imperativo da impossibilidade de seguir poetizando em vista do que acabou de ocorrer - isso desde os anos 1950, no impasse de se escrever poesia após a Segunda Guerra e a derrocada das vanguardas. E a única maneira de fazer com que haja qualquer coisa após a catástrofe é considerala, no limite, uma contingência, que pode (ou melhor: que poderia) ser evitada. O que se recusa, aqui, é toda e qualquer necessidade da catástrofe. Com o antiecologismo, a antipoesia de Parra supera a si mesma, transformando-se naquilo que ela sempre fora: uma profecia lúdica do apocalipse. "Texto de una voz que sale posterior al invierno nuclear". ${ }^{31}$

O raciocínio é propriamente paradoxal: daí a sua força. Como pode ser que a única maneira de evitar um destino catastrófico é assumir que ele é inevitável? Paradoxal que seja a proposição na sua forma puramente lógica ou sintática, ela é intuitiva: com efeito, empiricamente é perfeitamente aceitável a ideia de que o sujeito só reage a algum perigo no instante em que esse perigo se torna real e potencialmente inevitável. É neste instante que toda a força do sujeito é liberada, na tentativa, precisamente, de evitar o pior. O que Parra faz é colocar essa racionalidade pré-destinatória literalmente em jogo. Jogar com o apocalipse - profanar o apocalipse através da manipulação do discurso sagrado e ecológico. Todas as contradições assumidas. De certa forma, há certo parentesco formal entre a ironia e essa operação que poderíamos chamar de um autoengano do sujeito catastrofista: assim como a ironia, o autoengano também é um deslocamento do sujeito em relação ao próprio enunciado nesse caso, do sujeito enquanto aquele sabe de algo, mas que acredita no contrário daquilo que sabe. Sabe que o mundo acabou, que não há salvação, mas acredita ainda haver salvação exatamente por isso. $O$ autoengano do antiecologismo de Parra é precisamente aquele do sujeito que sabe que a catástrofe é inevitável, mas que acredita que ela, por isso mesmo, pode e deverá ser evitada.

A contradição, a mesma dos "Ecopoemas" e da pregação profana do Cristo de Elqui, é, então, a proposta de uma solução que se sabe, no fundo, impossível - mas que só a partir do momento em que é elaborada e percebida como impossível é que se pode contemplar a verdadeira amplitude do problema. ${ }^{32}$

\footnotetext{
${ }^{31}$ MORALES, Op. cit. p. 112.

32 A contradição interna desse tipo de raciocínio, dessa maneira de encarar o problema da relação entre catástrofe e destino, foi examinada em minúcias pelo filósofo alemão Frank Ruda
} 
A catástrofe, no antipoema dos anos 1970-80, é ao mesmo tempo aquilo que dispara o chamado ético do sujeito, e a condição da sua liberdade. Nos antipoemas, só há liberdade para o sujeito na medida em que ele se encontra absolutamente encurralado por um destino catastrófico inevitável. É aí, neste momento de desespero, que os atos verdadeiramente livres são exercidos: o ato de abrir mão da própria racionalidade, em busca de uma outra lógica, de um outro logos. Só há a iluminação da poesia da claridade parriana ${ }^{33}$, porque houve a bomba de Hiroshima e o campo de concentração, porque houve o golpe militar, e porque há, no futuro, o apocalipse. E isso, longe de ser uma fraqueza sua, uma espécie de lastro sinistro que ela estabelece com o mal, uma espécie de dívida histórica que ela tem para com o sofrimento da humanidade, é a sua força, pois é a garantia que ela se dá de que isso não deve, em hipótese alguma, se repetir. De certo modo a antipoesia de Parra está situada em um momento histórico específico, entre duas catástrofes: a catástrofe - ou as catástrofes, todas, do século $X X$-, e a possibilidade da sua repetição, na aniquilação total.

A posição antipoética é, na sua essência, impossível de ser sustentada. Não obstante, ela deve ser sustentada, porque a antipoesia é uma dança à beira do abismo. Um balança-mas-não cai perpétuo da espécie humana - o sujeito no limite da sua desintegração, e no auge da sua força. Seja como for, em tempos de descrença, do desmoronamento das chamadas "grandes narrativas", de violência, perseguição, catástrofe ecológica e desconcerto subjetivo e existencial, não só o riso e o humor se apresentam como uma saída, uma válvula de escape de liberdade, como é através do riso que talvez estejam as maiores chances de reação - é através de um humor como o do Cristo de Elqui ou dos "Ecopoemas" que a força mais subversiva encontra um canal para se manifestar em tempos perigosos e instáveis. Há mais verdade neste baile de máscaras disparatado do que a princípio se possa supor, e talvez a única saída em momentos catastróficos seja de fato colocar uma máscara e atirar de volta contra a realidade todo o seu desconcerto - isso é, dobrar a aposta da realidade.

(Abolishing freedom: a plea for a contemporary use of fatalism, 2016) e pelo teórico francês Jean-Pierre Dupuy (Economy and the future, 2011), que examina exatamente o mesmo problema a respeito da relação entre as esferas do sagrado e da economia. É tanto de Ruda quanto de Dupuy que estou tirando boa parte dessa lógica contraditória da catástrofe (Cf. RUDA, Frank. Abolishing freedom: a plea for a contemporary use of fatalism. Lincoln: University of Nebraska, 2016; DUPUY, Jean-Pierre. Economy and the future - a crisis of faith, trad. M. B. DeBevoise. Michigan State University, 2014).

${ }^{33} \mathrm{O}$ termo "poesia da claridade" foi usado por Parra em conferência de 1958 para descrever o projeto ao qual ele se vinculava, no início da obra, em oposição ao obscurantismo vanguardista da época. 
João Gabriel Mostazo Lopes é pesquisador, tradutor e dramaturgo, doutorando no Departamento de Teoria Literária e Literatura Comparada (DTLLC) da FFLCH/USP, orientado pela Profa. Dra. Viviana Bosi. Publicou artigos sobre antipoesia e literatura brasileira moderna. Desenvolve pesquisas sobre os seguintes temas: tradução poética, poesia modernista brasileira, vanguardas hispanoamericanas e antipoesia. É autor das peças de teatro Rompecabezas (publicada em 2017), A demência dos touros e Roda morta. Contato: j.mostazolopes@gmail.com 